\title{
Corrigenda
}

\section{FG has no added value in prediction of mortality after partial and radical nephrectomy for chromophobe renal cell carcinoma patients}

\author{
Malek Meskawi, Maxine Sun, Salima Ismail, Marco Bianchi, Jens Hansen, Zhe Tian, \\ Nawar Hanna, Quoc-Dien Trinh, Markus Graefen, Francesco Montorsi, Paul Perrotte and
} Pierre I Karakiewicz

Modern Pathology (2013) 26, 1152; doi:10.1038/modpathol.2013.42

Correction to: Modern Pathology advance online publication, 1 February 2013; doi: 10.1038/ modpathol.2012.230

The title of this article should be 'Fuhrman grade has no added value in prediction of mortality after partial or radical nephrectomy for chromophobe renal cell carcinoma patients.' The first sentence of the abstract should be 'Our objective was to test whether Fuhrman grade (FG) is applicable in the context of chromophobe renal cell carcinoma patients treated with partial and radical nephrectomy.' The first sentence of the Introduction should be 'Fuhrman grade (FG) represents an important prognostic factor in patients with renal cell carcinoma.'

\section{Duodenal follicular lymphoma lacks AID but expresses BACH2 and has memory B-cell characteristics}

Katsuyoshi Takata, Yasuharu Sato, Naoya Nakamura, Mami Tokunaka, Yukari Miki, Yara Yukie Kikuti, Kazuhiko Igarashi, Etsuro Ito, Hideo Harigae, Seiichi Kato, Eiko Hayashi, Takashi Oka, Yoshinobu Hoshii, Akira Tari, Hiroyuki Okada, Abd Alkader Lamia Mohamad, Yoshinobu Maeda, Mitsune Tanimoto, Tomohiro Kinoshita and Tadashi Yoshino

Modern Pathology (2013) 26, 1152; doi:10.1038/modpathol.2013.118

Correction to: Modern Pathology (2013) 26, 22-31; doi:10.1038/modpathol.2012.127; published online 17 August 2012.
In this article, the name of the 16th author in the byline is incorrect. The correct name is Lamia Abd Al-Kader. 